\title{
CO-PRECIPITATION AS A TOOL FOR EFFECTIVE DOPING OF MAGNESIUM IN ZINC OXIDE: STUDIES ON STRUCTURAL, OPTICAL AND PHOTOCATALYTIC PROPERTIES
}

\author{
U. Sachin Varma ${ }^{1}$, P. Gautham1, D.V. Ravi Kumar', K. M. Sreekanth",", \\ G. Sivasubramanian ${ }^{1}$ and K. M. Sreedhar ${ }^{2}$ \\ ${ }^{1}$ Department of Sciences, Amrita School of Engineering, Amrita Vishwa Vidyapeetham, \\ Coimbatore, India - 641112 \\ ${ }^{2}$ Department of Chemistry, Amrita School of Arts \& Sciences, Amrita Vishwa Vidyapeetham, \\ Amritapuri, India - 690525 \\ *E-mail : km_sreekanth@cb.amrita.edu
}

\begin{abstract}
Elimination of toxic compounds from our essential commodities such as water, air, foods etc. and provision for safe and clean basic needs is currently one of the most significant international topics for research, especially in food, water and air pollution control. Metal oxides have emerged as one of the most interesting materials in the current period owing to their potential catalytic properties. The II-VI metal oxides are gaining considerable attention in optoelectronics and in rectifying environmental issues due to their ability to produce charge carriers when accelerated with a sufficient amount of energy. The electronic structure, fluorescence and phosphorescence properties and charge transport abilities of the metal oxides have made them photo catalysts. In this paper, we report a precise investigation of structural, optical and photo catalytic properties of industrially and technologically important $\mathrm{ZnO}$ and $\mathrm{Mg}_{\mathrm{x}} \mathrm{Zn}_{(1-\mathrm{x})} \mathrm{O}$ nanoparticles. The materials were synthesized via chemical methods using solutions of zinc sulphate, sodium hydroxide, silver nitrate and magnesium sulphate. The structural, optical and photocatalytic properties of the synthesized samples were studied using X-ray diffractometer and UV-VIS spectrophotometer. The average crystallite size of the prepared samples is between 15 to $20 \mathrm{~nm}$. The optical band value of the $\mathrm{ZnO}$ nanoparticles was found $3.3 \mathrm{eV}$. The photocatalytic studies were conducted using an in-house built assembly and photocatalytic degradation of $\mathrm{Cr}$ was chosen as a reference. The synthesized $\mathrm{Mg}_{\mathrm{x}} \mathrm{Zn}_{(1-\mathrm{x})} \mathrm{O}$ has been observed as an excellent photocatalyst, and shown promising results for the degradation of $\mathrm{Cr}(\mathrm{VI})$.
\end{abstract}

Keywords: Metal oxides, Semiconductors, Zinc Oxide, Magnesium oxide, Crystallite size, Band gap, Photocatalysis, Hexavalent and trivalent Chromium, Photo catalyst.

(C) RASĀYAN. All rights reserved

\section{INTRODUCTION}

In recent years, the world, mostly the advanced nations, facing tremendous issues like energy shortage and environmental problems related to the remediation of hazardous waste and polluted air and water contaminants. One of the promising solutions for the above-mentioned problems is "Semiconductor photo-catalysis". Since it is a "green technology" for the splitting of $\mathrm{H}_{2} \mathrm{O}$, inactivating/eliminating all kinds of organic and inorganic contaminants in the presence of sunlight under ambient conditions ${ }^{1,2}$. Photo-catalysis is the process of employing a catalyst that is used for enhancing chemical reactions in the presence of light. A photocatalyst is a material that absorbs light and produces electron-hole pairs that facilitate chemical changes of the participants and reproduces its chemical composition after each interval of interactions with light ${ }^{3-8}$. The photocatalysts based on semiconductor metal oxides are usually used as activators that catalyze the radical chain reaction in photocatalytic oxidation. Also these materials can be used in the photo catalytic treatment of dyes in waste-water, due to low cost and other tunable properties,

Rasayan J. Chem., 11(4), 1491-1500(2018) http://dx.doi.org/10.31788/RJC.2018.1144000

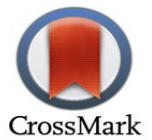


without any significant loss in their photo catalytic activity ${ }^{9}$.Nanoparticles of metal oxide semiconductors have achieved various functionalities that are not experimentally found in bulk materials and have been studied extensively due to their unique structural, optical, electronic, magnetic, photo catalytic, antitumor, antimicrobial, wound healing and anti-inflammatory properties ${ }^{10-21}$. Over the last 10 years, there is an exponential growth in the scientific and engineering interest on semiconductor photo-catalysis ${ }^{21}$. Out of this practical interest, there is a comprehensive research effort in developing novel photocatalytic materials for better efficiency under solar illumination. Low-cost metal oxide semiconductor photocatalysts with higher photocatalytic efficiency offer enormous potential applications for the purification of four elements in "five great elements" such as earth, water, air and space along with the conversion of photon energy into chemical energy. As a wide band gap $\left(\mathrm{E}_{\mathrm{g}}=3.37 \mathrm{eV}\right.$ at $\left.300 \mathrm{~K}\right)$ semiconductor with large exciton binding energy $(60 \mathrm{MeV})^{23}$, Zinc oxide $(\mathrm{ZnO})$ is a promising and versatile material, that has been intensively studied in the field of blue-violet light emitting diodes (LEDs), ultraviolet detectors, solar cells, field-effect transistors (FETs), sensors, and photo-catalysis ${ }^{23}$. Band-gap engineering is important in tuning the optical, magnetic and electrical properties and to develop new structural designs ${ }^{23,24}$. In this context, Magnesium oxide $(\mathrm{MgO})$ is one of the promising candidates for altering (increasing) the $\mathrm{E}_{\mathrm{g}}$ of $\mathrm{ZnO}$ due to small lattice mismatch of $\mathrm{MgO}$ with $\mathrm{ZnO}$. Being non-toxic and multi-functional, $\mathrm{ZnO}$ is an effective material in green technology ${ }^{19,22}$. Accordingly, from the viewpoint of semiconductor photochemistry, the role of photocatalyst is to accelerate specific redox reaction in the presence of irradiated semiconductors In general, the photochemical activities are based on the direct excitation of the target molecules by visible light or UV. Absorbing materials are used in photo catalytic reactions, which are energized by light and are able to transfer electrons from their excited states to the molecules to be converted. Electrons which is in the conduction band may photo catalytically reduce the organic pollutant ${ }^{25,26}$. A considerable amount of chromium $(\mathrm{Cr})$ is widely used in several industries such as stainless steel, plating, leather tanning, mining, paint making and others ${ }^{21,26}$. Chromium metal is an essential trace element for human health. However, the raw industrial wastes contain the hexavalent chromium, $\mathrm{Cr}(\mathrm{VI})$, which is highly toxic, carcinogenic, may cause pulmonary congestions, and liver damage ${ }^{21,26}$. Since it is highly toxic in nature, $\mathrm{Cr}(\mathrm{VI})$ has been considered as one of the most noxious wastes that are to be removed especially from drinking water. According to the World Health Organization (WHO), the limit of $\mathrm{Cr}(\mathrm{VI})$ in drinking water is $0.05 \mathrm{ppm}^{21}$. On the other hand, trivalent chromium, $\mathrm{Cr}(\mathrm{III})$, is eco-friendly. It is an important trace element for regulating the insulin function in the human body. Consequently, the reduction of $\mathrm{Cr}(\mathrm{VI})$ to $\mathrm{Cr}$ (III) is crucial in environmental issues ${ }^{21}$.

There are different chemical methods for reducing $\mathrm{Cr}(\mathrm{VI})$. The photocatalytic reduction with semiconducting metal oxides is regarded as a smart green technology not only because of its low cost, high effectiveness and non-usage of any harmful reducing agents but also the reduction proceeds without the production of any secondary pollutants. A variety of semiconducting catalysts such as $\mathrm{TiO}_{2}, \mathrm{ZnO}$, $\mathrm{ZnS}, \mathrm{ZnIn}_{2} \mathrm{~S}_{4}$, andLa $\mathrm{Ti}_{2} \mathrm{O}_{7}$ have been used for the photoreduction of $\mathrm{Cr}(\mathrm{VI})^{21,27,28}$. Upon irradiation with light/UV, in these II-VI metal oxide semiconducting materials, electrons move from valence band (VB) to conduction band $(\mathrm{CB})$ leaving holes in $\mathrm{VB}^{21}$. Electrons in the conduction band photocatalytically reduce the organic/inorganic pollutant. In the industrial sector, the installation cost of such photocatalytic reactors is very high and the main problem associated with this reactor configuration is the issue of scaleup for commercial use purpose ${ }^{29}$. With a clear objective in achieving a cost-effective and easily assembled unit, a new photoreactor (built in-house) is developed with UV LED strip as the light source. Simultaneous monitoring of multiple analyses can be easily done with this system. In this present work, we synthesized $\mathrm{Mg}_{\mathrm{x}} \mathrm{Zn}_{(1-\mathrm{X})} \mathrm{O}$. The structural and optical properties of the obtained materials were characterized. Also, we are contented to report for the first time that we have developed a new low-cost photocatalytic reactor (built in-house) with UV LED light strip as a light source.

\section{EXPERIMENTAL}

\section{Materials}

Analytical grade chemicals were used in this experiment without any further purification. Zinc sulphate $\left(\mathrm{ZnSO}_{4} .7 \mathrm{H}_{2} \mathrm{O}\right)$, sodium hydroxide $(\mathrm{NaOH})$, magnesium sulphate $\left(\mathrm{MgSO}_{4} .7 \mathrm{H}_{2} \mathrm{O}\right)$, cetyl 
trimethylammonium bromide $(\mathrm{CTAB})$, deionized water, nitric acid $\left(\mathrm{HNO}_{3}\right)$, ethanol $\left(\mathrm{C}_{2} \mathrm{H}_{5} \mathrm{OH},>99 \%\right)$, isopropyl alcohol $\left(\mathrm{C}_{3} \mathrm{H}_{8} \mathrm{O}\right)$ and Whatman No. 40 filter paper were used in this experiment. All the chemicals are of purity $\geq 98 \%$ and were obtained from Sigma-Aldrich.

\section{Synthesis of $\operatorname{Mg}_{\mathrm{x}} \mathrm{Zn}_{(1-\mathrm{x})} \mathrm{O}(\mathrm{x}=0,1,5$ and $10 \%)$ Nanoparticles}

The scheme that was followed for the synthesis of our compounds is mechanic assisted chemical coprecipitation technique ${ }^{30}$ in which a surfactant was also used.

\section{General Procedure}

For the synthesis of zinc oxide, the required aqueous solution of zinc sulphate was prepared. To this, a solution contains both $\mathrm{NaOH}$ and $\mathrm{CTAB}$ was added dropwise with constant stirring. After the addition, stirring was continued for 2 hours in order to ensure the completeness of the reaction. The turbid solution obtained was kept undisturbed for the settlement of the precipitate and the supernatant was discarded. The precipitate, zinc hydroxide $\left(\mathrm{Zn}(\mathrm{OH})_{2}\right)$, obtained was thoroughly cleaned washing with deionized water, ethanol and acetone to remove unwanted salt and impurities. The prepared $\mathrm{Zn}(\mathrm{OH})_{2}$ was heated at $150^{\circ} \mathrm{C}$ for two hours in order to convert it into $\mathrm{ZnO}$. It was then allowed to cool and ground in order to assist for size reduction ${ }^{30}$. The chemical equations representing the preparation as follows:

$$
\begin{gathered}
\mathrm{ZnSO}_{4} .7 \mathrm{H}_{2} \mathrm{O}+\underset{\mathrm{NaOH}}{2 \mathrm{Nn}(\mathrm{OH})_{2}} \rightarrow \mathrm{Zn}(\mathrm{OHO})_{2}+\mathrm{H}_{2} \mathrm{O} \\
\mathrm{Na} \mathrm{SO}_{4}+7 \mathrm{H}_{2} \mathrm{O} \\
\end{gathered}
$$

To prepare the doped samples, i.e. $\mathrm{Mg}_{\mathrm{x}} \mathrm{Zn}_{(1-\mathrm{x})} \mathrm{O}$, different molar concentrations of $\mathrm{MgSO}_{4} .7 \mathrm{H}_{2} \mathrm{O}$ were added to the solution of $\mathrm{ZnSO}_{4} \cdot 7 \mathrm{H}_{2} \mathrm{O}$ followed by a solution contains both $\mathrm{NaOH}$ and CTAB. The flow chart of the chemical reaction isgivenintheFig.-1.

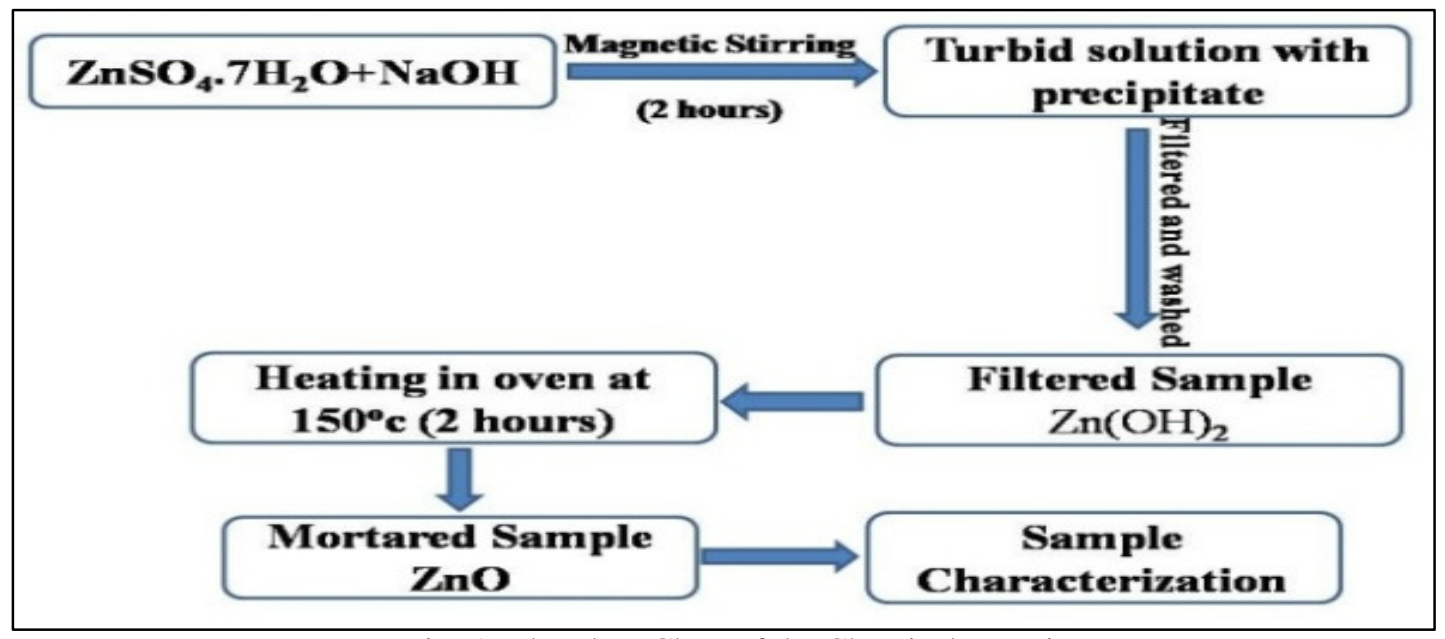

Fig.-1: The Flow Chart of the Chemical Reaction

\section{Detection Method}

In order to investigate various properties of the prepared samples, they have to be characterized using various techniques which can give information on their structural and optical properties. In the present work, the structural analysis of the prepared samples was carried out by X-ray diffraction (XRD with $\mathrm{Cu}$ $\mathrm{K} \alpha, \lambda=1.5405 \AA$ ) and optical characterization was done through UV/Vis spectroscopy. In our studies, we made use of Philip PW1700 XRD and JASCO UV-Vis NIR spectrometer (V-670).

\section{Instrumentation-Photocatalytic Reactor}

A line diagram of the photoreactor assembly is shown in Fig.-2. The photoreactor was built in-house, with a clear objective in achieving a cost-effective and easily assembled unit, for simultaneous monitoring of multiple analyses. The housing of the unit was made of the galvanized sheet which was hammered down to a neat cabin of $2 \times 1 \times 2$ feet dimension. The cabin was fit with a door of the same material to enable easy 
handling of the sample. The inside of the cabin, including the door, was decorated with 2" thermal insulation with proper rubber beadings to win a compact setting and minimize any heat loss that may occur during operation. The inner side of the cabin was cemented with a UV LED strip (150V-265V AC input, power $0.2 \mathrm{~W}$ ) in series of three tiers of equal dimensions. No strip was affixed on the roof of the cabin in order to avoid any discomfort. A magnetic stirrer was placed inside the cabin to agitate the contents of the $100 \mathrm{~mL}$ borosil@ beaker, which was used as the reactor. The open beaker attracted maximum radiation and the thin walls facilitated in this action. The whole of the cabin was maintained at a static temperature of $296 \mathrm{~K}$ with the help of an insulated-ducted air-heat exchanger of $300 \mathrm{kcal} / \mathrm{h}$ capacity. This profusely helped to sufficiently cool the reactor and maintain uniform temperature distribution without any gradient formation.

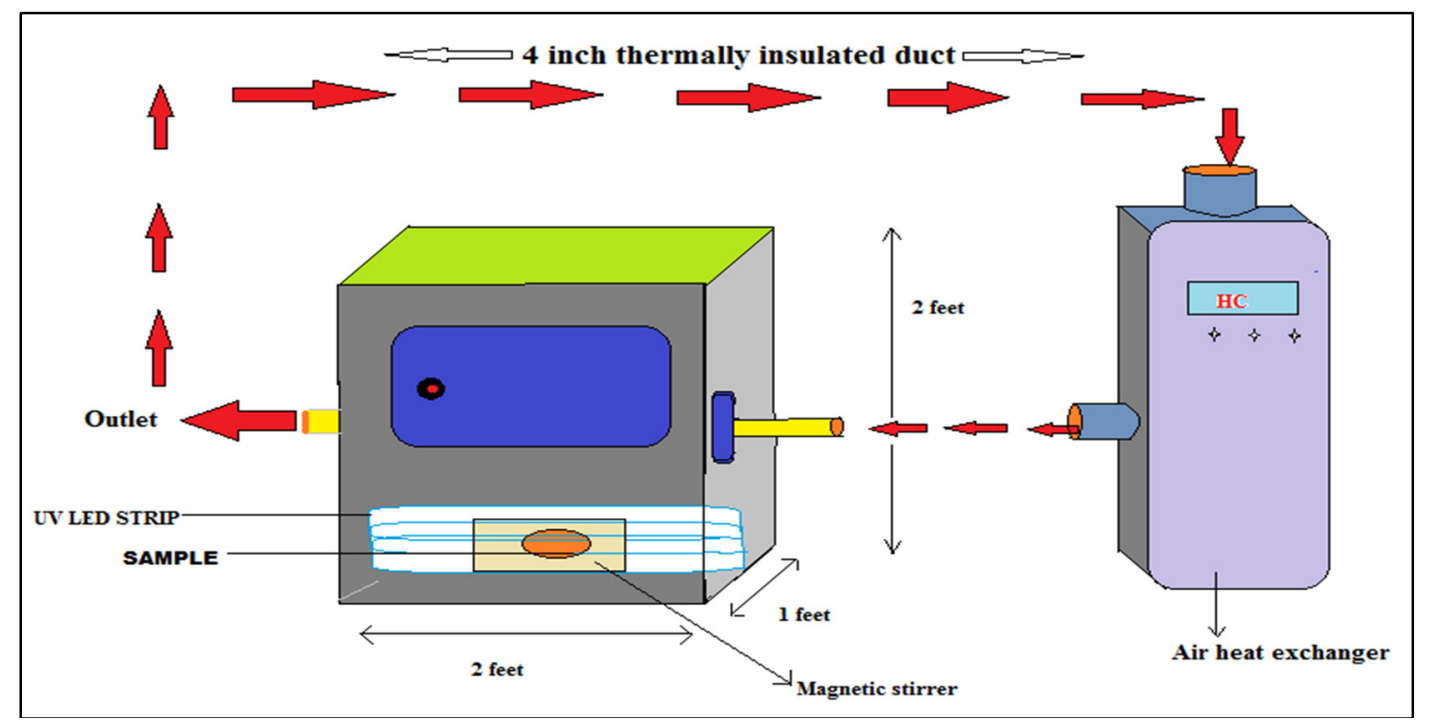

\section{Analytical Discussion}

Fig.-2: Line-Diagram of the Photo-Reactor Assembly

The photocatalytic experiments were studied under UV light using RGB 300 UV LED strip (150V-265V AC input).For every experiment, $100 \mathrm{~mL}$ of $50 \mathrm{ppm} \mathrm{Cr}(\mathrm{VI})$ solution containing $10 \mathrm{~mL}$ of oxalic acid as hole scavenger was taken in a $500 \mathrm{~mL}$ beaker. The photocatalyst, $20 \mathrm{mg}$, was added to the solution and was shaken in an orbital shaker at $200 \mathrm{rpm}$. Initially, the solution was shaken in dark for 15 min to reach an adsorption-desorption equilibrium of $\mathrm{Cr}(\mathrm{VI})$ over the catalyst. This was followed by irradiation of UV light under aerobic condition. The aliquots were collected in a regular interval during photoreduction. Diphenylcarbazide (DPC) was used as the indicator to follow the photocatalytic reaction. The residual $\mathrm{Cr}(\mathrm{VI})$ concentration was determined using UV-Vis spectrophotometer at $540 \mathrm{~nm}$ after complexation with DPC. This is repeated for Mg-doped samples.

\section{RESULTS AND DISCUSSION}

The structure of the samples was characterized by XRD. The XRD patterns of $\operatorname{Mg}_{x} \operatorname{Zn}_{(1-x)} \mathrm{O}$ samples are shown in the Fig.-3. The peaks at $31.5^{\circ}, 34.28^{\circ}, 36.16^{\circ}, 47.45^{\circ}, 56.45^{\circ}, 62.8^{\circ}$ and $67.8^{\circ}$ indicate that the samples are highly crystalline. Comparing with JCPDS data 36-1451, lattice planes are identified as (100), (002), (101), (102), (110), (103) and (112), respectively, indicating hexagonal wurtzite structure of $\mathrm{ZnO}$. The broadening of the peaks gives an idea about the small particle size of the synthesized $\mathrm{ZnO}$.

From the XRD data, it is clear that there is a shift of diffraction peaks towards higher angles with the increase in dopant concentration. This indicates that $\mathrm{Zn}^{2+}$ is substituted by $\mathrm{Mg}^{2+}$ in the host lattice. The ' $\mathrm{a}$ ' and ' $c$ '-axis lattice constants for (100) and (002) peaks were calculated ${ }^{31}$ using the relations, $a=$ $\frac{\lambda}{\sqrt{3} \sin \theta}$ and $\mathrm{c}=\frac{\lambda}{\sin \theta}$. The calculated lattice parameters are given in the Table-1. The lattice constants ' $\mathrm{a}$ ' and 'c' of $\mathrm{Mg}_{\mathrm{x}} \mathrm{Zn}_{(1-\mathrm{x})} \mathrm{O}$ are similar to pure $\mathrm{ZnO}$ at room temperature [JCPDS card no. 36-1451]. The lattice 
RASĀYAN $J$. Chem.

Vol. 11 | No. 4 |1491 - 1500| October - December | 2018

constant ' $a$ ' and 'c' are reduced monotonically, i.e., ' $a$ ' is reduced from 3.2729 to $3.2445 \AA$ and 'c' is reduced from 5.3446 to $5.1977 \AA$. It is owing to the fact that the $\mathrm{Mg}^{2+}$ replaced $\mathrm{Zn}^{2+}$ from $\mathrm{ZnO}$ and lodged itself in the interstitial position. Also, the decrease of lattice parameters is ascribed to comparatively lower ionic radii of $\mathrm{Mg}^{2+}$ compared to $\mathrm{Zn}^{2+}$ ions ${ }^{32}$.

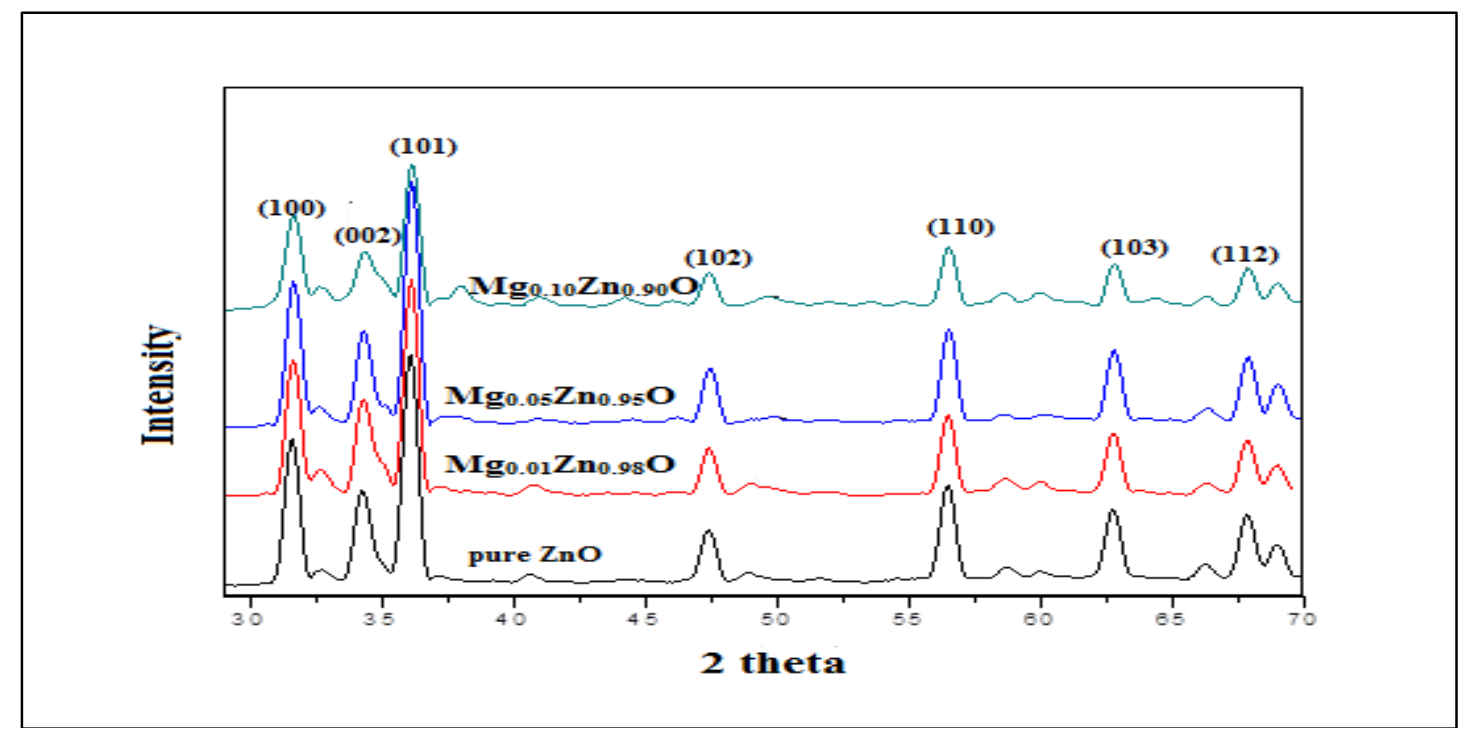

Fig.-3: XRD Pattern of $\mathrm{Mg}_{\mathrm{x}} \mathrm{Zn}_{(1-\mathrm{x})} \mathrm{O}$ Nanoparticles for Different Doping Concentrations

Table-1:The Calculated Lattice Parameters for $\mathrm{Mg}_{\mathrm{x}} \mathrm{Zn}_{(1-\mathrm{x})} \mathrm{O}$

\begin{tabular}{c|c|c|c}
\hline Sample & Lattice parameter (a) $\AA$ & Lattice parameter $(\mathrm{c}) \AA$ & Volume $\left(\AA^{3}\right)$ \\
\hline $\mathrm{ZnO}$ & 3.2729 & 5.3446 & 49.5788 \\
\hline $\mathrm{Mg}_{0.01} \mathrm{Zn}_{0.99} \mathrm{O}$ & 3.2718 & 5.3412 & 49.5145 \\
\hline $\mathrm{Mg}_{0.05} \mathrm{Zn}_{0.95} \mathrm{O}$ & 3.2684 & 5.3373 & 49.3746 \\
\hline $\mathrm{Mg}_{0.10} \mathrm{Zn}_{0.90} \mathrm{O}$ & 3.2445 & 5.1977 & 47.3840 \\
\hline
\end{tabular}

The average crystallite size (D) was calculated using the Scherer's formula ${ }^{24}$ given as $\mathrm{D}=\frac{0.89 \lambda}{\beta \cos \theta}$, where $\lambda=1.514 \times 10^{-10} \mathrm{~m}$ and $\beta$ is full width at half maximum (FWHM). The calculated crystallite sizes of the samples are tabulated in Table-2.

Table-2: Calculated Crystalline Size for the Prepared Samples

\begin{tabular}{c|c|c|c|c}
\hline Sample & Peak(deg) & FWHM $(\beta)$ & Crystalline Size(D) nm & Plane \\
\hline $\mathrm{ZnO}$ & 36.0334 & 0.5457 & 13.8465 & 101 \\
\hline $\mathrm{Mg}_{0.01} \mathrm{Zn}_{0.99} \mathrm{O}$ & 36.0323 & 0.4518 & 16.7243 & 101 \\
\hline $\mathrm{Mg}_{0.05} \mathrm{Zn}_{0.95} \mathrm{O}$ & 36.5740 & 0.5160 & 14.4968 & 101 \\
\hline $\mathrm{Mg}_{0.10} \mathrm{Zn}_{0.90} \mathrm{O}$ & 36.6398 & 0.5100 & 14.9221 & 101 \\
\hline
\end{tabular}

As $\mathrm{Mg}$ is doped, it is seen immediately that the size of the particles increases. The crystallite size as a function of dopant concentration is shown in the Fig.-4.It can also be seen that the crystallite size decreases up to $5 \% \mathrm{Mg}$-doped $\mathrm{ZnO}$ and then remains almost constant with the increase in $\mathrm{Mg}$ concentration. The gradual increase of $\mathrm{Mg}$ doping progressively reduces the concentration of zinc in the system. The reason for the decrease in size can be explained in two ways. Firstly, the decrease in crystal size can be attributed to the formation of $\mathrm{Mg}$-substituted $\mathrm{ZnO}(\mathrm{Mg}-\mathrm{O}-\mathrm{Zn})$ solid solution which inhibits the growth of crystal grains ${ }^{33}$. Secondly, the decrease in crystallite size as a function of $\mathrm{Mg}$ content can be explained by the Zener pinning effect ${ }^{34}$. There are a variety of inherent defects present in $\mathrm{ZnO}$ with different ionization energies such as oxygen vacancy $\left(\mathrm{V}_{\mathrm{O}}\right)$, zinc vacancy $\left(\mathrm{V}_{\mathrm{Zn}}\right)$, oxygen interstitials $\left(\mathrm{O}_{\mathrm{i}}\right)$ and zinc interstitials $\left(\mathrm{Zn}_{\mathrm{i}}\right)^{23}$. Due to these crystal defects and imperfections, the expansion of grain boundaries gets restricted in a crystal which is called Zener pinning effect ${ }^{34}$. In the present study, after 
doping, the number of $\mathrm{V}_{\mathrm{O}}$ present in the $\mathrm{ZnO}$ lattice may be increased. These oxygen vacancies may restrict the growth of the crystallites owing to the Zener pinning effect.

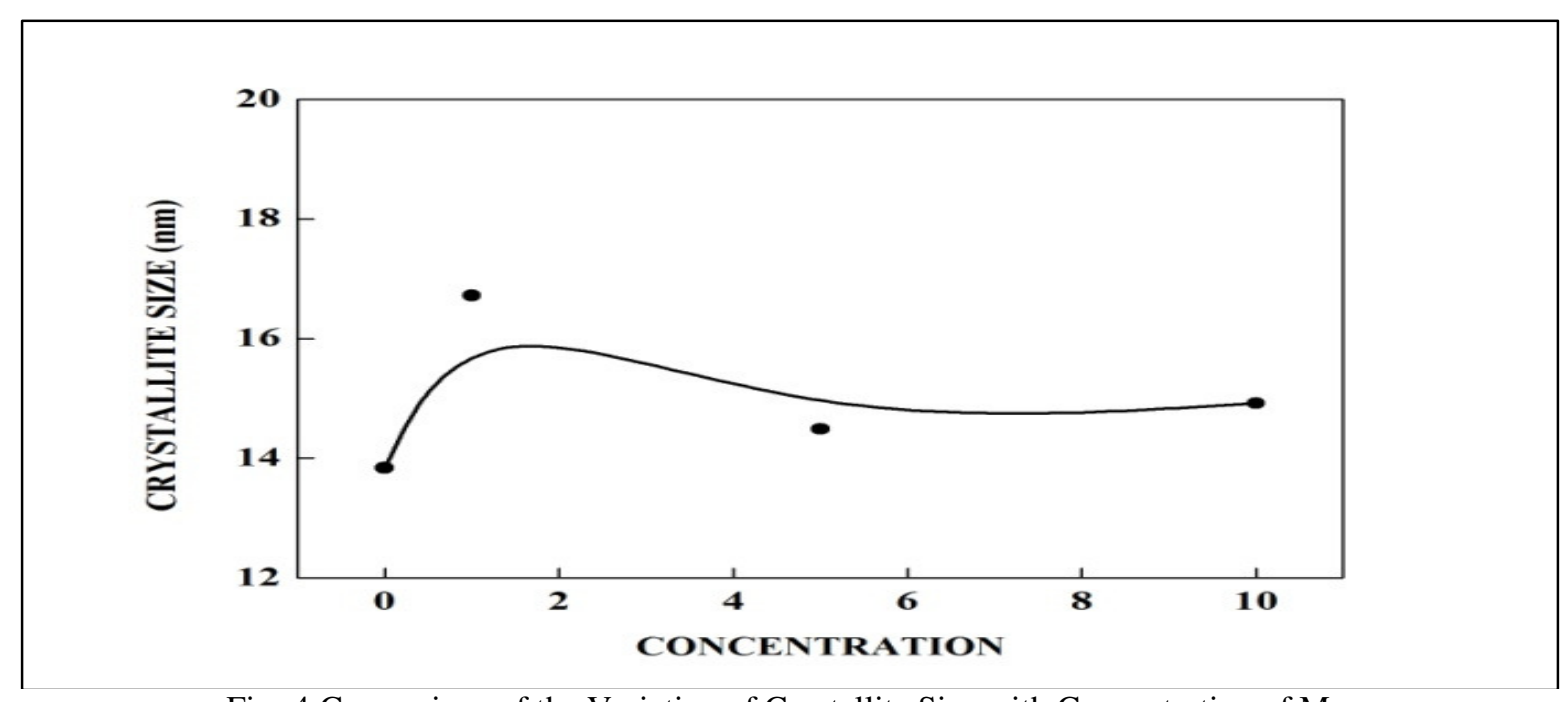

Fig.-4:Comparison of the Variation of Crystallite Size with Concentration of Mg

\section{UV-Vis Characterization}

The room temperature optical measurements were performed using a UV-visible-near infrared spectrophotometer. The absorbance spectra of $\mathrm{Mg}_{\mathrm{x}} \mathrm{Zn}_{(1-\mathrm{x})} \mathrm{O}$ nanoparticles are shown in the Fig. -5 and is observed that the absorbance wavelength decreases(blue shift) with an increase in doping concentration. This indicates the widening of $\mathrm{E}_{\mathrm{g}}$, which agrees with the reported experimental results ${ }^{32,33,35}$. The room temperature $\mathrm{E}_{\mathrm{g}}$ for $\mathrm{ZnO}$ can be tuned to fit the desired applications by doping with suitable divalent elements without affecting the charge carrier concentrations in $\mathrm{ZnO}$. In particular, $\mathrm{Mg}$ doping increases the $\mathrm{E}_{\mathrm{g}}$ further into the UV range and it results in a blue shift in the absorption spectra.

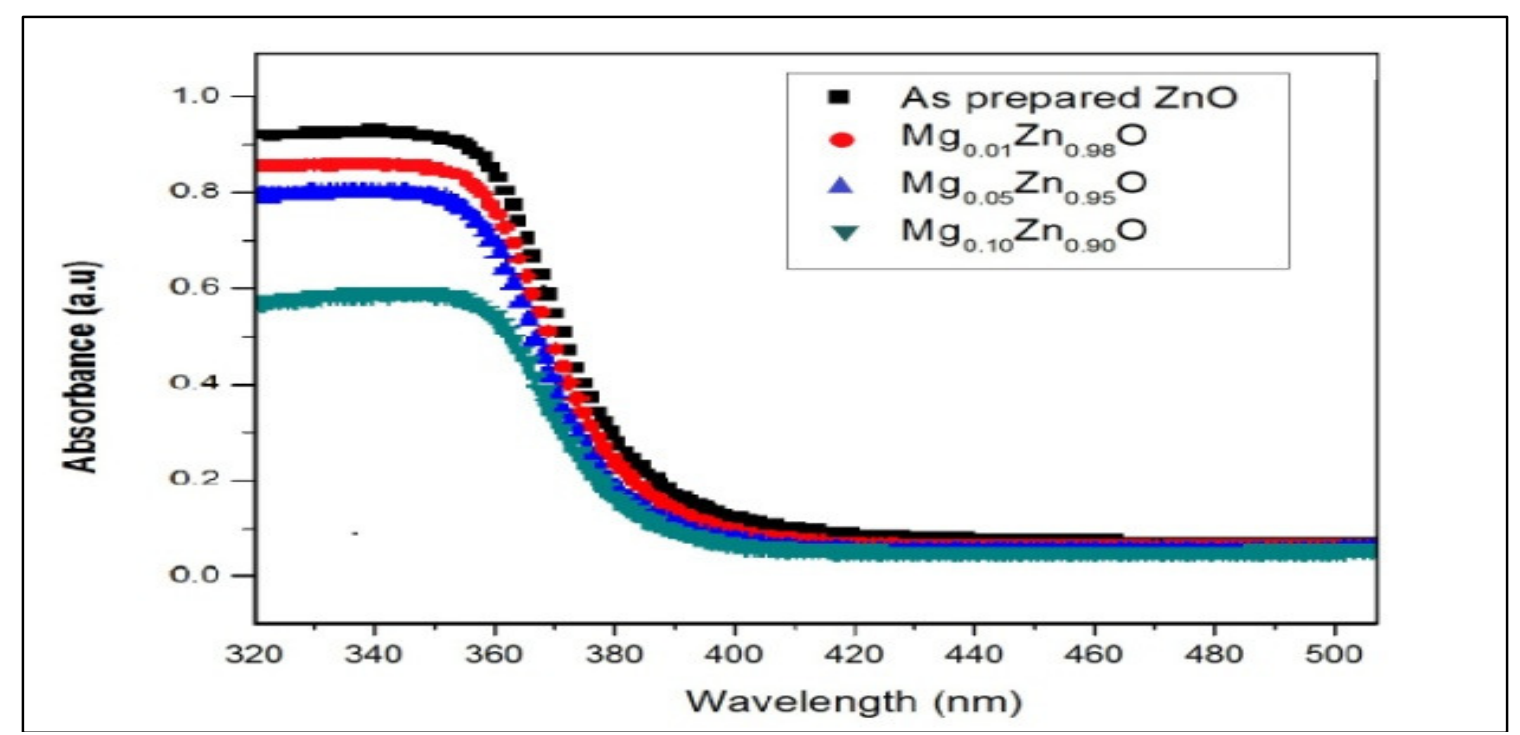

Fig.-5: The Absorbance Spectra of $\mathrm{ZnO}$ and $\mathrm{Mg}$ doped $\mathrm{ZnO}$ Samples

The Tauc plot for $\mathrm{Mg}_{\mathrm{x}} \mathrm{Zn}_{(1-\mathrm{x})} \mathrm{O}$ samples in comparison with $\mathrm{ZnO}$ is given in the Fig.-6. The $\mathrm{E}_{\mathrm{g}}$ obtained from the plot is tabulated in the Table-3.

The shifting of absorbance spectra to the shorter wavelength depends upon a number of reasons. Blue shift commonly occurs when the particle size is decreased. When the Bohr's radius is higher than the particle size, this shift can be described by the effect of quantum confinement ${ }^{33}$. However, the crystallite 
size of all $\mathrm{Mg}_{\mathrm{x}} \mathrm{Zn}_{(1-\mathrm{x})} \mathrm{O}$ nanoparticles prepared in this studies is further than the Bohr's radius, thus the change in $\mathrm{E}_{\mathrm{g}}$ values might be influenced by other parameters. Here, the increase in a blue shift or the band gap can be explained on the basis of Burstein-Moss effect ${ }^{32}$. $\mathrm{ZnO}$ is an n-type semiconductor and the Fermi level lies inside the conduction band (CB). Doping of $\mathrm{Mg}$ donates a large number of electrons due to the lesser electron affinity of $\mathrm{MgO}$ in contrast to $\mathrm{ZnO}$. Consequently, the Fermi level for $\mathrm{Mg}_{\mathrm{x}} \mathrm{Zn}_{(1-\mathrm{X})} \mathrm{O}$ samples is located at a higher position. Hence, the blue shift or increase in $\mathrm{E}_{\mathrm{g}}$ is due to the radiative recombination of these electrons.

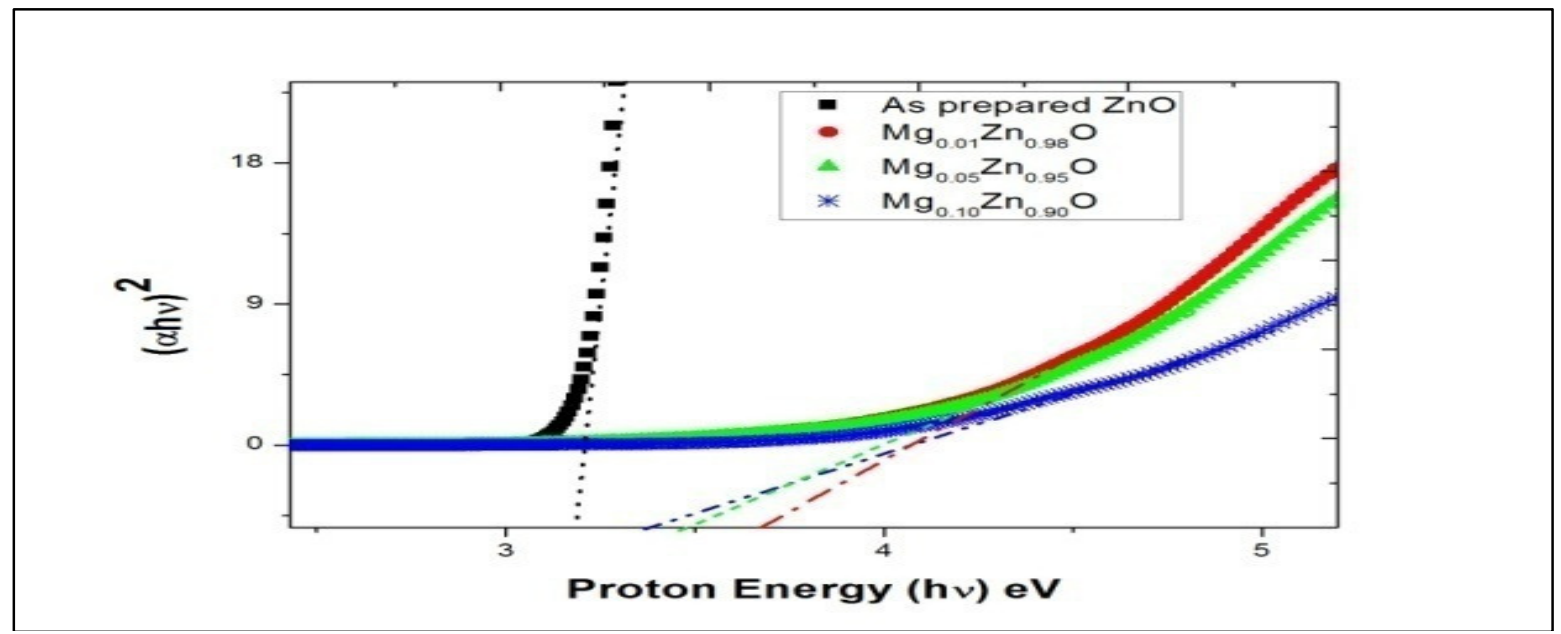

Fig.-6: Optical Absorption Spectra (Tauc plot) of $\mathrm{ZnO}$ and $\mathrm{Mg}$-doped $\mathrm{ZnO}$ samples

\section{Photocatalytic Study}

Upon irradiation, the electrons jump from VB to CB, leaving holes in VB. The reduction potential for $\mathrm{Cr}(\mathrm{VI}) / \mathrm{Cr}(\mathrm{III})$ with respect to a normal hydrogen electrode (NHE) is $1.33 \mathrm{~V}$. If the chosen catalytic material's $\mathrm{CB}$ edge is above $1.33 \mathrm{~V}$, the electron, which is in the $\mathrm{CB}$ may photocatalytically reduce $\mathrm{Cr}(\mathrm{VI})$ to $\mathrm{Cr}(\mathrm{III})^{21}$. Photocatalytic degradation of $\mathrm{Cr}$ was chosen as a reference and the characteristic absorption of the $\mathrm{Cr}$ seen at the UV-Visible range was selected for monitoring the photocatalytic reduction process of $\mathrm{ZnO}$ nanoparticles. Fig.-7 and 8 represent the typical curves for the normalized concentrations of the $\mathrm{Cr}$ solution as a function of UV irradiation time over the as-prepared $\mathrm{ZnO}$ and $\mathrm{Mg}_{0.01} \mathrm{Zn}_{0.99}$ Onanoparticles. In comparison with slow degradation process of the $\mathrm{Cr}$ under the UV irradiation with undoped $\mathrm{ZnO}$ nanoparticles, adding of $\mathrm{Mg}$-doped $\mathrm{ZnO}$ nanoparticles markedly accelerated the reduction of $\mathrm{Cr}$ with increasing $\mathrm{Mg}$ concentration.

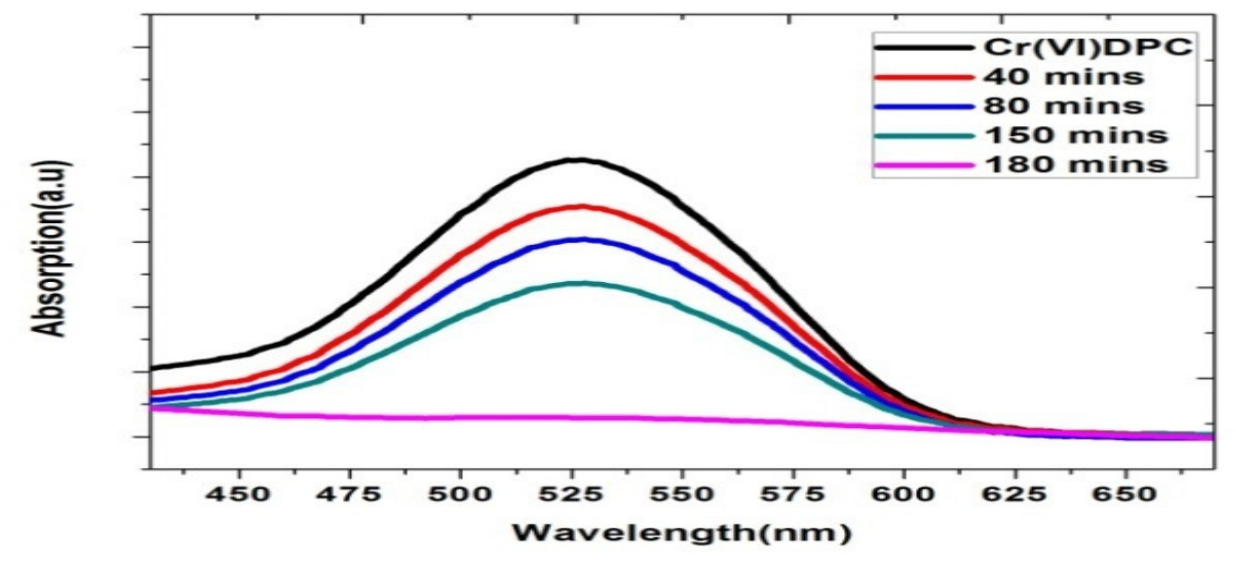

Fig.-7: Optical Absorbance Spectra of Photocatalytic Degradation of Cr(VI) Solution as a Function of UV irradiation on $\mathrm{ZnO}$ 
RASĀYAN J. Chem.

Vol. 11 | No. 4 |1491 - 1500| October - December | 2018

Table-3: The $\mathrm{E}_{\mathrm{g}}$ determined from the Tauc Plot

\begin{tabular}{c|c}
\hline Sample & Energy Gap(eV) \\
\hline $\mathrm{ZnO}$ & 3.28 \\
\hline $\mathrm{Mg}_{0.01} \mathrm{Zn}_{0.99} \mathrm{O}$ & 3.38 \\
\hline $\mathrm{Mg}_{0.05} \mathrm{Zn}_{0.95} \mathrm{O}$ & 3.44 \\
\hline $\mathrm{Mg}_{0.10} \mathrm{Zn}_{0.90} \mathrm{O}$ & 3.69 \\
\hline
\end{tabular}

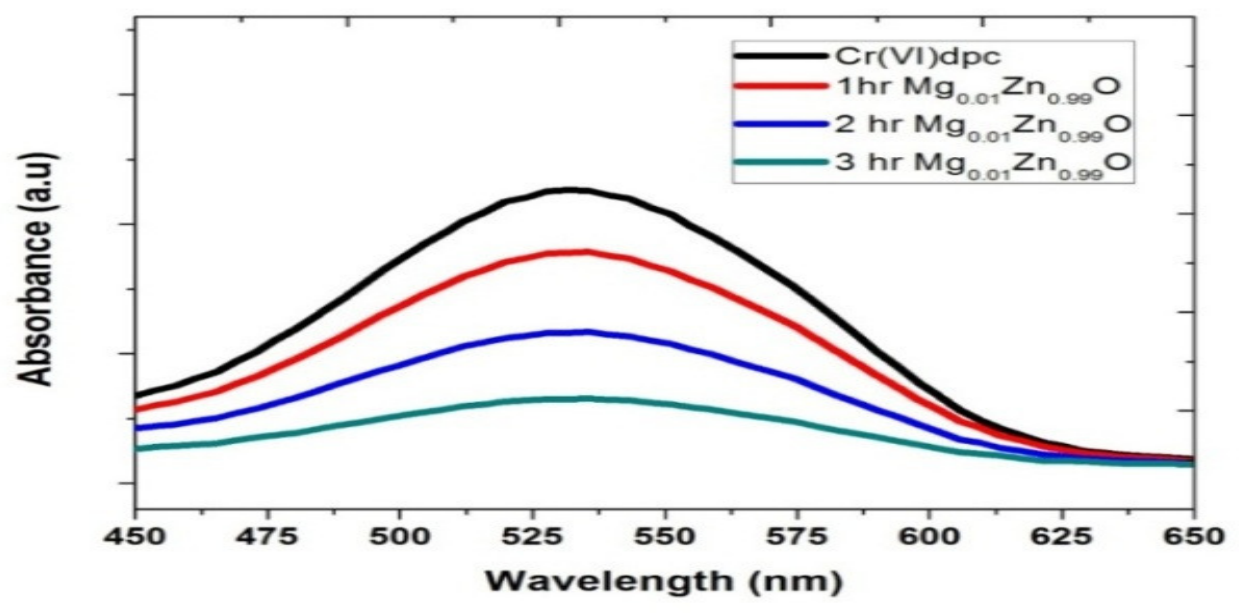

Fig.8-: Optical absorbance spectra of photocatalytic degradation of Cr(VI) solution as a function of UV irradiation on $\mathrm{Mg}_{0.01} \mathrm{Zn}_{0.99} \mathrm{O}$

\section{Effect of Doping on Photo-Catalysis}

From Fig.-9 showing the photocatalytic degradation of $\mathrm{Cr}(\mathrm{VI})$ solution as a function of UV irradiation for a constant time (120 min) on $\mathrm{Mg}_{\mathrm{x}} \mathrm{Zn}_{(1-\mathrm{x})} \mathrm{O}$ nanoparticles, it is observed that the photocatalytic activity is increasing as the doping concentration increases.

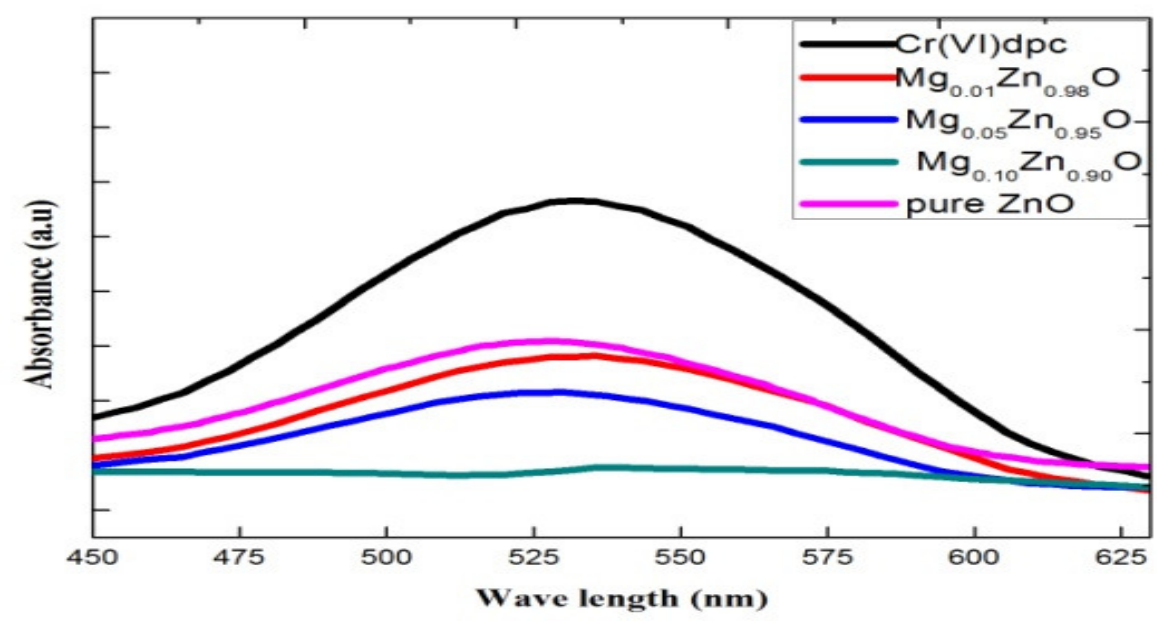

Fig.-9:Room temperature optical absorbance spectra of photocatalytic degradation ofCr(VI) solution as a function of

UV irradiation for a constant time (120 min) on $\mathrm{Mg}_{\mathrm{x}} \mathrm{Zn}_{(1-\mathrm{x})} \mathrm{O}$ nanoparticles

This acceleration in photocatalytic activity (as doping concentration increases) could be due to the presence of vacancies and trace metal ions doped in the $\mathrm{ZnO}$ matrix which can effectively trap the photogenerated hole-electron pairs with the help of hole scavengers like oxalic acid ${ }^{21}$.The superficial potential 
trap of photo-generated electron-hole pairs lengthen the lifetime of electrons and holes and increases photocatalytic activity $11,27,28$. Therefore, $\mathrm{ZnO}$ and $\mathrm{Mg}_{\mathrm{x}} \mathrm{Zn}_{(1-\mathrm{x})} \mathrm{O}$ have been observed as excellent photocatalysts. The development of such photocatalysts is considered as a promising material in the largescale utilization of heterogeneous photo-catalysis via visible or UV to deal with contaminated water and other environmental pollutions.

\section{CONCLUSION}

In this present work, we synthesized undoped and $\mathrm{Mg}$-doped $\mathrm{ZnO}$ nanoparticles by the co-precipitation method. From XRD analysis, it is seen that $\mathrm{Mg}^{2+}$ ions exactly replaced the $\mathrm{Zn}^{2+}$ ions without affecting the crystal structure. We noticed that $\mathrm{E}_{\mathrm{g}}$ of the $\mathrm{ZnO}$ nanoparticle varies with $\mathrm{Mg}$ doping. These synthesized $\mathrm{Mg}_{\mathrm{x}} \mathrm{Zn}_{(1-\mathrm{x})} \mathrm{O}$ samples have been observed as excellent photocatalysts. The $\mathrm{Mg}_{\mathrm{x}} \mathrm{Zn}_{(1-\mathrm{x})} \mathrm{O}$ photocatalyst showed promising results for the degradation of $\mathrm{Cr}(\mathrm{VI})$ for detoxification and environmental remediation.

\section{ACKNOWLEDGMENT}

I acknowledge the financial, academic and technical support of Amrita Vishwa Vidyapeetham through AMRITA/IFRP-26/2015/16/08. I am cordially thankful to all members of the Department of Sciences, Amrita School of Engineering, Amrita Vishwa Vidyapeetham, Coimbatore, India.

\section{REFERENCES}

1. Andrew Mills and Stephen Le Hunte, Journal of Photochemistry and Photobiology A: Chemistry, 108, 1(1997), DOI:10.1016/S1010-6030(97)00118-4.

2. Monu Bhardwaj and Neelam, Journal of Basic and Applied Engineering Research, 2(22),1957(2015)

3. T. A. Arun, Chacko, D. K., Madhavan, A. A., Deepak, T. G., Anjusree, G. S., Sara, T., Ramakrishna, S., Nair, S. V. and A. Nair, S., RSC Advances, 4, 1421(2014), DOI:10.1039/C3RA45021J .

4. P. Amornpitoksuk, S. Suwanboon, S. Sangkanu, A. Sukhoom, N. Muensitand J. Baltrusaitis, Powder Technol.,219, 158(2012), DOI: 10.1016/j.powtec.2011.12.032.

5. Sumetha Suwanboon, Pongsaton Amornpitoksuk, Apinya Sukolrat and Nantakan Muensit, Ceramics International, 39, 2811(2013), DOI: 10.1016/j.ceramint.2012.09.050.

6. K. Ravichandran, P. Sathish, S. Snega, K. Karthika, P. V. Rajkumar, K. Subha and B. Sakthivel, Powder Technology, 274, 250(2015), DOI: 10.1016/j.powtec.2014.12.053.

7. K. Ravichandran, S. Snega, N. Jabena Begum, L. Rene Christena, S. Dheivamalar and K. Swaminathan, Philosophical Magazine, 94, 22, 2541(2014), DOI: 10.1080/14786435.2014.921349.

8. Adil and Al-Mayouf, Journal of Saudi Chemical Society, (2015), DOI: 10.1016/j.jscs.2015.04.003.

9. Zhibin Wu, Xingzhong Yuan, Jin Zhang, Hou Wang andLongbo Jiang, Guangming Zeng, Chem. Cat. Chem., 9, 1(2016), DOI: 10.1002/cctc.201600808.

10. Sreekanth K. Mahadeva, Quan, Z. Y., Fan, J. C., Albargi, H. B., Gehring, G. A., Riazanova, A., Belova, L., and Rao, K. V., In Symposium F-Oxide Semiconductors and Thin Films, 1494, 115(2013), DOI: $10.1557 /$ opl.2013.260.

11. Uma Maheswari, A., Saravana Kumar, S. and Sivakumar, M., J. Nanosci. Nanotechnol., 13(6), 4409 (2013), DOI:10.1166/jnn.2013.7150.

12. Sreekanth K. Mahadeva, Fan, J., Biswas, A., Rao, G. M., Sreelatha, K. S., Belova, L., and K Rao, V., Materials Express, 3, 328(2013), DOI: 10.1166/mex.2013.1131.

13. Uma Maheswari A., Mohan S. R., Saravana Kumar S. and Sivakumar M., Ceram. Int., 40, 5 6561(2014), DOI: 10.1016/j.ceramint.2013.11.109.

14. Sreekanth K. Mahadeva, Fan, J., Biswas, A., Sreelatha, K. S., Belova, L., and Rao, K. V., Nanomaterials, 3, 486(2013), DOI: 10.3390/nano3030486.

15. P. T. Sudheesh Kumar, Lakshmanan, V. K., Anilkumar, T. V., Ramya, C, Reshmi, P., Unnikrishnan, A. G, Nair, S. V, and Jayakumar, R., ACS Applied Materials and Interfaces, 4, 2618(2012), DOI: 10.1021/am300292v.

16. B. H. N. Reddy, T. M. Mohan Kumar, and Lakshmi, V. V., Journal of Bionanoscience, 11, 59(2017), DOI: $10.1166 /$ jbns.2017.1412.

17. Rex Jeya Rajkumar S, MSA Muthukumar Nadar and Paulraj Mosae Selvakumar, Glob. J. Nanomed., 3, 1(2017), DOI:10.19080/GJN.2017.03.555605.

DOPING OF MAGNESIUM IN ZINC OXIDE 
18. D. Saratchand A., Sreekanth K. M., Krishnan N. Cherupally, and Rao, K. V., Journal of Cancer Therapy, 2, 666(2011), DOI: 10.4236/jct.2011.25089.

19. B. Das, M. I. Khan, R. Jayabalan, S. K. Behera , S.I.Yun , S.K.Tripathy , A.Mishra, Sci. Rep., 6, 36403(2016), DOI: 10.1038/srep36403.

20. Sangeetha Gunalana, Rajeshwari Sivaraja, and Venckatesh Rajendran, Progress in Natural Science: Materials International,22(6), 693(2012), DOI: 10.1016/j.pnsc.2012.11.015.

21. Ravikiran Nagarjuna, Swapna Challagulla, Ramakrishnan Ganesan and Sounak Roy, Chemical Engineering Journal, 308, 59(2017), DOI: 10.1016/j.cej.2016.09.044.

22. K. T. Shalumon, Anulekha, K. H., Nair, S. V., Chennazhi, K. P., and Jayakumar Rangasamy, International Journal of Biological Macromolecules, 49, 247(2011), DOI: 10.1016/j.ijbiomac.2011.04.005.

23. J.C. Fan, K.M. Sreekanth, Z. Xie, S.L. Chang, and K.V. Rao, Progress in Materials Science, 58(6), 874(2013), DOI: 10.1016/j.pmatsci.2013.03.002.

24. Sreekanth K. Mahadeva, Ph. D. Thesis, Department of Material Science and Engineering, KTH-The Royal Institute of Technology, Stockhom, Sweden,(2013)

25. S. S. Shinde, C. H. Bhosaleand K. Y. Rajpure, Catalysis Reviews: Science and Engineering, 55(1), 79(2013), DOI: 10.1080/01614940.2012.734202.

26. Francesco Parrino and Leonardo Palmisano, Mini-Reviews in Organic Chemistry, 15, 157(2018), DOI: $10.2174 / 1570193 X 14666171117151718$.

27. G. Cappelletti, C.L. Bianchi, and S. Ardizzone, Appl. Catal. B: Environ., 78, 193(2008), DOI: 10.1016/j.apcatb.2007.09.022.

28. Y. Ku, and I.L. Jung, Water Res.,35, 135(2001), DOI: 10.1016/S0043-1354(00)00098-1.

29. Mukherjee, P.S. and A.K. Ray, Chemical Engineering and Technology, 22(3), 253(1999), DOI: $10.1002 /($ SICI) $1521-4125$.

30. S. Das and V. C. Srivasatava, Smart Science, 4(4), 190(2016), DOI: 10/1080 /23080477.2016.1260425.

31. F. K. Shan, B. I. Kim, G. X. Liu, Z. F. Liu, J. Y. Sohn, J. Lee, B. C. Shin, and Y. S. Yu, J. Appl. Phys., 95, 4772 (2004), DOI:10.1063/1.1690091.

32. Parmod Kumar, Hitendra K. Malik, Anima Ghosh, R. Thangavel, and K. Asokan, Appl. Phys. Lett., 102, 221903 (2013), DOI: 10.1063/1.4809575.

33. S. Suwanboon, P. Amornpitoksuk, A. Haidoux, J.C. Tedenac, Journal of Alloys and Compounds, 462, 335(2008), DOI:10.1016/j.jallcom.2007.08.048.

34. R.W. Kelsall, I.W. Hamley, and M. Geoghegan, Nanoscale Science and Technology, John Wiley and Sons, West Sussex, (2005)

35. Samson B. Woodley, Alexey A. Sokol, Richard A. Catlow, Abdullah A. Al-Sunaidi, and Scott M. Woodley, J. Phys. Chem. C,117, 27127(2013), DOI: 10.1021/jp4084635.

[RJC-4000/2018] 